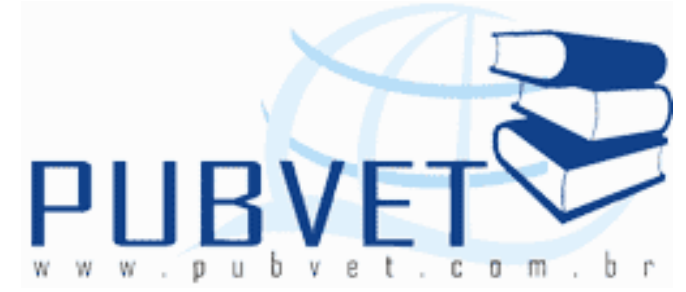

PUBVET, Publicações em Medicina Veterinária e Zootecnia.

\title{
Distocia em Jabuti Piranga (Chelonoidis carbonaria) - relato de caso
}

Victor Hugo Martins Ferreira ${ }^{1}$; Moacir Carretta Júnior ${ }^{2}$; Camila Fernanda das Chagas $^{1}$; Idelvânia dos Anjos Nonato ${ }^{1}$; Sâmara Turbay Pires ${ }^{2}$

${ }^{1}$ Estudante do Curso de Medicina Veterinária - UNIVIÇOSA. Viçosa- MG

2 Professor do Curso de Medicina Veterinária - UNIVIÇOSA. Viçosa- MG

\section{Resumo}

Os jabutis são répteis do gênero Chelonoidis, da família dos testudinídeos, a segunda maior família da ordem Testudines em número de espécies. Dentre os principais problemas reprodutivos encontrados nesta espécie podemos destacar a distocia, que raramente tem sido relatada em répteis selvagens, porém é relatada em $10 \%$ da população de répteis em cativeiro, por ano. 0 diagnóstico se baseia na diferenciação da forma obstrutiva e não obstrutiva acompanhada dos exames complementares como exames radiográficos. 0 objetivo desde trabalho foi relatar o caso clínico de distocia em um Jabuti Piranga que após tratamento com ocitocina e gluconato de cálcio conseguiu botar todos os ovos, evitando assim possíveis complicações na sua saúde, inclusive quanto ao risco de morte.

Palavras-chave: Répteis, quelônios, radiografia, ocitocina, gluconato de cálcio. 


\title{
Dystocia in Red-footed tortoise (Chelonoidis carbonaria) - case report
}

\begin{abstract}
The tortoises are reptiles of the genus Chelonoidis, the family Testudinidae, the second largest family of the order Testudines in number of species. Among the major reproductive problems found in this species we can highlight the dystocia, which has rarely been reported in wild reptiles, however it is reported in $10 \%$ of the population of captive reptiles per year. The diagnosis is based on the differentiation of obstructive and non-obstructive accompanied by additional tests such as X-rays. The goal since the study was to report the clinical case of dystocia in a Red-footed tortoise that after treatment with oxytocin and calcium gluconate could put all the eggs, thus avoiding possible complications in your health, including the risk of death.
\end{abstract}

Keywords: reptiles, chelonians, radiography, oxytocin, calcium gluconate.

\section{Introdução}

Os jabutis são répteis do gênero Chelonoidis, ordem dos Quelônios, família dos testudinídeos, a segunda maior família da ordem Testudines em número de espécies, pertencente à classe dos répteis. (PINHEIRO \& MATIAS apud MATIAS, 2006).

Os jabutis são animais terrestres, de corpo robusto, carapaça bem arqueada, membros locomotores cilíndricos e fortes, apropriados para suportar o casco pesado e caminhar em ambientes rústicos. No Brasil, existem três espécies de jabutis que são: jabuti-piranga (Chelonoidis carbonaria), jabutitinga (Chelonoidis denticulata) e jabuti argentino (Chelonoidis chilensis) que é rara (CUBAS \& BAPTISTOTTE, 2007).

O jabuti-piranga apresenta um colorido mais vivo, de cabeça e patas vermelhas, podendo chegar em torno de $15 \mathrm{Kg}$. Os machos são maiores que as fêmeas, em média $30 \mathrm{~cm}$ e as fêmeas $28 \mathrm{~cm}$, chegando no máximo de 40-50 $\mathrm{cm}$, e podem viver cerca de 80 anos (LOBO, 2003). É um animal onívoro, ou 
seja, alimenta-se de proteína animal (pequenos vertebrados, minhocas, insetos, etc) e fibras vegetais (figura 1), e durante o inverno, tem o hábito de hibernar-se e pode ficar cerca de dois meses sem sair do casco, nem mesmo para comer (BORGES, 2003).

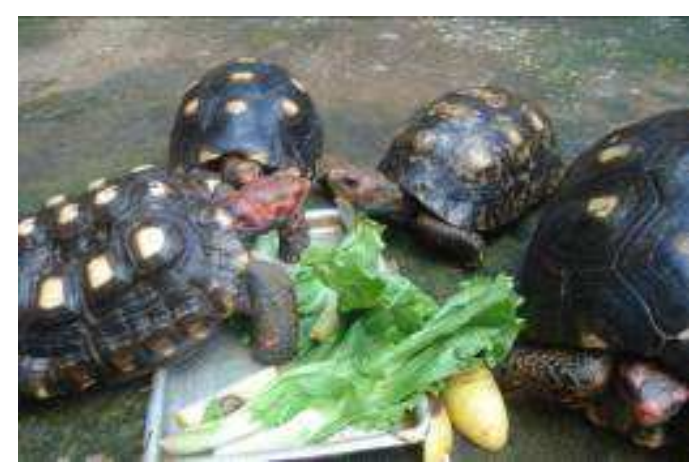

figura 1- Grupo de animais e cativeiro no momento da alimentação

Essa espécie abrange uma ampla variedade geográfica, a partir do leste dos Andes, estende-se da Colômbia passa pelo sul, através do leste do Brasil para o Rio de Janeiro, e a oeste com a Bolívia, Paraguai e norte da Argentina. Também é nativa do Panamá e da ilha de Trinidad, no Caribe; habita florestas tropicais, secas, espinhosas e temperadas e evita áreas lamacentas (ERNST, 1997).

As instruções normativas 117 e 118 de 1997 do IBAMA protegem a criação e a comercialização dos jabutis, que está na lista das espécies brasileiras ameaçadas de extinção, autorizando apenas a criação de duas espécies: o jabuti-piranga e o jabuti-tinga (IBAMA ${ }^{\mathrm{a}}, 2012$; IBAMA $^{\mathrm{b}}, 2012$ ).

A reprodução do jabuti é ovípara, sendo que o fotoperíodo, temperatura, ciclo térmico e a oferta de alimentos são fatores importantes na determinação de sua sazonalidade. A maturidade sexual ocorre por volta dos 5 a 7 anos, atingindo o número entre 6 a 20 ovos por postura. A incubação ocorre numa temperatura entre 28 a $31^{\circ} \mathrm{C}$ e a umidade relativa em torno de $85 \%$, por um período de 60 a 90 dias, havendo controvérsia entre autores a respeito desse período (CUBAS \& BAPTISTOTTE, 2007). Na época da desova, normalmente de 
abril a junho, a fêmea cava buracos na terra de mais ou menos $20 \mathrm{~cm}$ e neles deposita os ovos, indo de aproximadamente 7-20 ovos, ficando incubados de seis a nove meses (IBAMA, 2002). Esta espécie é de fácil adaptação reprodutiva em cativeiro (JEPSON, 2010).

O plastrão (parte inferior do casco) é côncavo nos machos e planos nas fêmeas, sendo este o principal caráter de dimorfismo sexual (figura 2). Os machos são territorialistas e costumam brigar, principalmente na época da reprodução, quando se confrontam para chamar a atenção das fêmeas. O vencedor ganha o direito de acasalar-se. (LEITE, 2012).

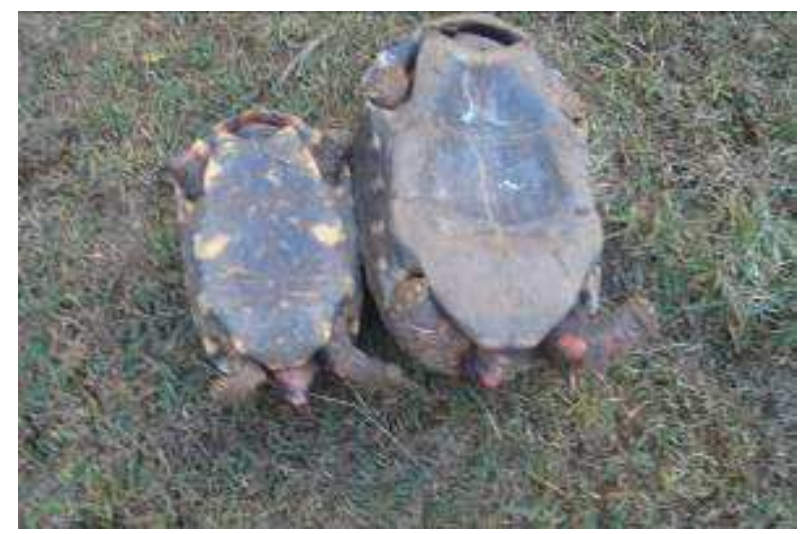

figura 2- Diferenciação entre machos (direita) e fêmeas (esquerda) pela visualização do plastrão.

A distocia tem sido raramente relatada em répteis selvagens, porém é narrada em $10 \%$ da população de répteis em cativeiro, por ano. O termo é usado mais amplamente como qualquer situação de fracasso pela fêmea no processo reprodutivo. Como resultado da permanência dos ovos dentro da fêmea, diferentes distúrbios fisiológicos podem se desenvolver, podendo culminar no óbito do animal. O quadro de distocia é diagnosticado após um intervalo superior a 48 horas de ocorrência do início da ovoposição (MADER, 1996).

A etiologia da distocia pode ser atribuída a uma vasta gama de situações, podendo ser classificada de duas formas: obstrutiva quando há alguma coisa impedindo o fluxo normal dos ovos e não obstrutiva quando está relacionado 
ao ambiente, estado físico, nutricional e manejo inadequado (CUBAS \& BASPTISTOTTE, 2007).

Este trabalho tem como objetivo relatar um caso de distocia ou dificuldade na oviposição, em um jabuti-piranga atendido no Hospital Veterinário da Faculdade de Ciências Biológicas e da SaúdeFACISA/UNIVIÇOSA.

\section{Relato de Caso}

Um jabuti fêmea (Chelonoidis carbonaria) com idade aproximada de 10 anos, pesando $2,750 \mathrm{~kg}$, foi encaminhado ao Hospital Veterinário da UNIVIÇOSA, com a queixa de ter botado apenas um ovo no dia anterior, o que é bem incomum, pois normalmente, esses animais tem uma postura de 7 a 20 ovos.

Ao exame físico detectou-se que o animal estava levemente desidratado e havia presença de escudos epidermais em formato piramidal indicando possível quadro de doença oesto-metabólica. Baseado na anamnese do animal e nos sinais clínicos suspeitou-se de distocia.

Para confirmar a hipótese, o animal foi encaminhado para o setor de diagnóstico por imagem onde foi realizada uma radiografia no posicionamento dorsoventral para visualização da cavidade celomática. Ao exame radiográfico foram visualizadas três estruturas ovaladas radiopacas confirmando a presença de ovos. Os ovos visualizados não apresentavam alterações e aparentemente estavam em perfeitas condições para a incubação, porém retidos (figura 3). 


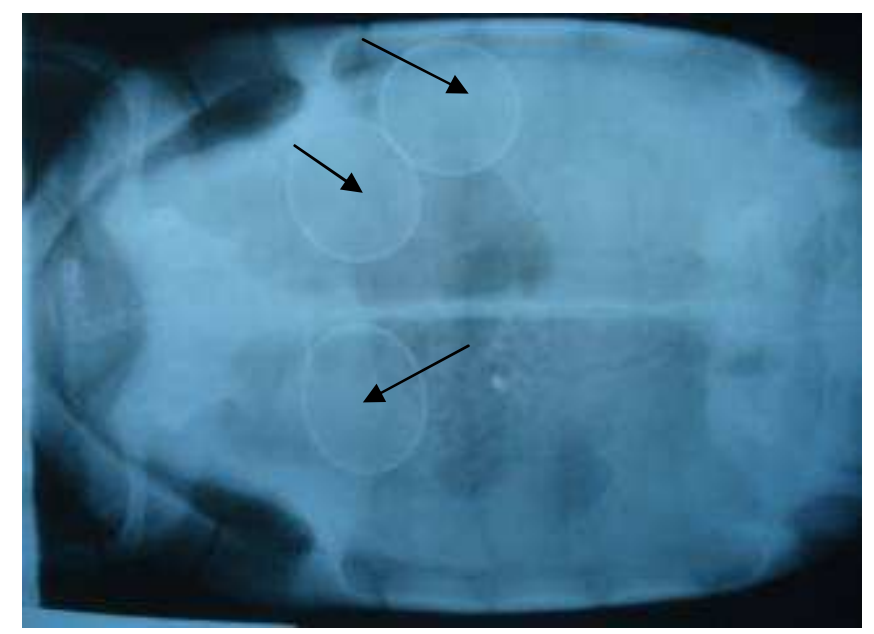

Figura 3- Diagnóstico radiográfico de distocia em jabuti piranga (Chelonoidis carbonaria), com presença de três ovos retidos.

Após o diagnóstico, foi recomendado manejo ambiental com objetivo de proporcionar melhores condições para a realização da postura. Primeiramente foi sugerido que o animal fosse colocado em um solo macio (areia) para que realizasse a ovoposição. Entretanto, esse manejo não foi bem sucedido. Após quatro dias sem realização da postura dos ovos restantes foi realizada aplicação de $30 \mathrm{mg} / \mathrm{kg}$ de gluconato de cálcio IV (pelo seio occipital) com o animal em ambiente aquecido; após 30 minutos foi aplicado 25 UI/KG de Ocitocina IM (no membro torácico), com repetição após 30 minutos de metade da dose de ocitocina. E posteriormente no tempo de 15 minutos da segunda dose o animal fez a postura do primeiro ovo seguido rapidamente pelos demais (figura 4).

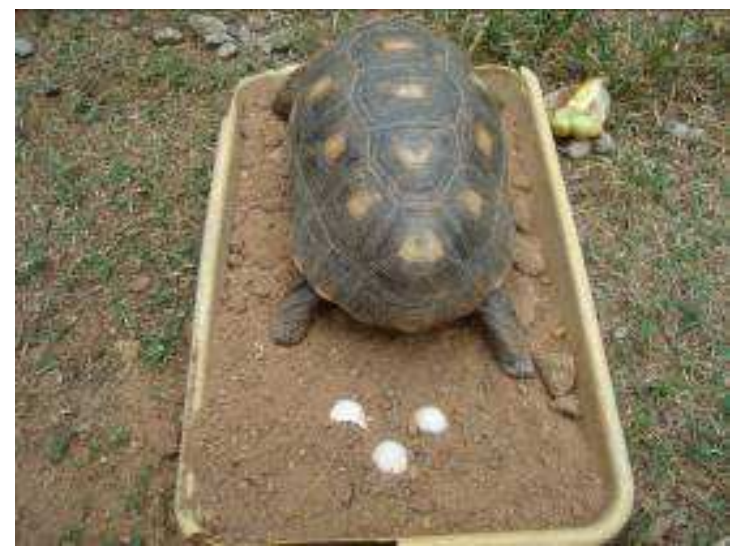

figura 4- Foto tirada minutos após a desova. 


\section{Resultado e Discussão}

Mader (1996) relata que a taxa de eficiência da ocitocina no tratamento de distocias não obstrutivas em quelônios é de aproximadamente $90 \%$ em animais que apresentam este quadro a 48 horas, sendo que esta eficiência decai com o passar do tempo. No caso deste trabalho o animal apresentou uma distocia com duração de 96 horas e mesmo estando acima do tempo relacionado com a maior eficiência do protocolo de associação de gluconato de cálcio (IV) com ocitocina (IM) os resultados foram completamente satisfatórios, uma vez que o animal colocou os ovos em exatos 15 minutos após a administração da segunda dose de ocitocina (IM).

Em casos de suspeita de distocia, deve-se recorrer sempre aos exames complementares como auxilio no diagnóstico de retenção de ovos. Dentre os principais estão o Raios- $X$, acompanhada de punção celomática quando necessário. A hematologia e a cultura microbiológica também são úteis $\mathrm{e}$, em caso de óbito, deverá proceder à necropsia (JEPSON, 2010).

Quando se trata de distocia em répteis temos que levar em consideração o tipo de distocia em questão e o estado físico do animal, uma vez que o caso poderá se agravar e levar o animal ao óbito. Sendo a distocia confirmada não obstrutiva, o protocolo clínico é o mais indicado, administrando sempre o gluconato de cálcio (IV) antes da ocitocina para uma melhor contração uterina; e não obtendo resultados, a ocitocina poderá ser novamente administrada em doses maiores após 30 a 60 minutos (CUBAS \& BAPTISTOTTE, 2007). Nos casos em que não ocorre resposta frente ao tratamento com associação de gluconato de cálcio com ocitocina o animal deve ser submetido à celiotomia para a remoção cirúrgica dos ovos.

\section{Considerações Finais}

Atualmente, é crescente o número de adeptos a criarem jabutis como animais de companhia, mesmo sem informações precisas sobre o manejo 
FERREIRA, V.H.M. et al. Distocia em Jabuti Piranga (Chelonoidis carbonaria) - relato de caso. PUBVET, Londrina, V. 6, N. 36, Ed. 223, Art. 1479, 2012.

desses em cativeiro. Muitos destes proprietários não sabem como proceder ao aparecimento de sinais de quaisquer anormalidades apresentados pelos mesmos. Por esse motivo, é papel do Médico Veterinário a conscientização do proprietário que esta é uma espécie de animal silvestre, protegido por lei, o que implica que a única forma legalizada para aquisição de exemplares desta espécie é através de criatórios legalizados. Cabe também ao profissional veterinário o tratamento de possíveis anormalidades como distocias, utilizando de medidas clínicas menos invasivas que podem salvar a vida desses animais.

\section{Referência Bibliográfica}

BORGES, A. 2003. "Dicas de Como alimentar seu Jabuti" (On-line). Acessado em 28 de junho de 2012 em http://www.noticiaanimal.com.br

CUBAS, P. H.; BAPTISTOTTE, C. Chelonia (Tartaruga, cágado, jabuti). In: CUBAS, Z. S.; SILVA, J. C. R. Tratado de Animais Silvestre - Medicina Veterinária. Roca, p.86-119. São Paulo. 2007

DENARDO, D. Dystocias. In: MADER, D. R. Reptile Medicine and Surgery. Elsevier. 2a Ed, p. 787-792. Flórida. 2006.

ERNST, C., R. Altenburg, R. Barbour. 1997. "Geochelone carbonaria "(On-line). Tartarugas do Mundo. Acessado em 28 de junho de 2012 em http://nlbif.eti.uva.nl

IBAMA $^{a}$. Portaria no 117-n de 15 de outubro de 1997. Acessado em 04 de setembro de 2012. Disponível em http://www.ibama.gov.br/fauna/legislacao/port_117_97.pdf

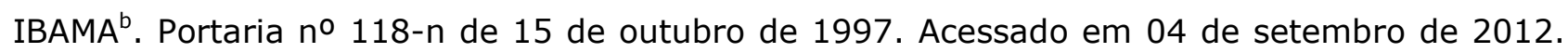
Disponível em http://www.ibama.gov.br/fauna/legislacao/port_118_97.pdf

JEPSON, L. Jabutis e Cágados. In: Clínica de Animais Exóticos. Elsevier, p. 358-410. Rio de Janeiro. 2010

LEITE, L. 2012. "Chelonoidis carbonária" (On-line). Acessado em 28 de junho de 2012 em http://www.terradagente.com.br/fauna

LOBO, D. et al. Ocorrência de Gheochelone (Reptilia - Testudinidae) no Abismo de Simão Dias, Sergipe, Brasil. In: XXVII Congresso Brasileiro de Espeleologia. Anais XXVII Congresso Brasileiro de Espeleologia. Januária - MG. 2003.

MATIAS, C. A. R.; ROMÃO, M. A. P.; ROGÉRIO, T.; BRUNO, S. F. Aspectos Fisiopatológicos da Retenção de Ovos em Japutipiranga ( Geochelone carbonária Spix, 1824). Ciência Rural. v.36, p.1494-1500. Santa Maria. 2006. 